ORIGINAL RESEARCH PAPER

PERORAL ENDOSCOPIC MYOTOIMY (POEM) FOR ACHALASIA CARDIA: PROSPECTIVE CASE SERIES OF 50 PATIENTS.

\section{General Surgery}

KEY WORDS: Achalasia cardia(AC), Lower esophageal sphincter (LES), Laparoscopic Hellers cardio-myotomy(LHM), Peroral endoscopic myotomy (POEM), High resolution manometry(HRM)

\section{Dr. Shantaram Gulve* \\ Dr. Mandar Doiphode}

\section{Dr. Kalpesh Patil}

Assistant Professor Department of General Surgery MIMER Medical College Talegaon Dabhade Pune. *Corresponding Author

Assistant Professor Department of General Surgery MIMER Medical College Talegaon Dabhade Pune.

Assistant Professor Department of Surgery MIMER Medical College Talegaon Dabhade Pune.

Achalasia cardia (AC) is a primary motility disorder of the esophagus, characterized by absent peristalsis along with incomplete relaxation of lower esophageal sphincter (LES). Laparoscopic Heller's cardio-myotomy (LHM) was considered the gold standard for treatment of AC. POEM (Per Oral Endoscopic Myotomy) is fast emerging as an alternative modality of treatment for AC. It is as effective and with minimal morbidity but there have been reports of postprocedure reflux esophagitis in some percentage of patients. Here in our prospective study we have tried to analyze the efficacy and safety profile and complications of POEM in AC patients who underwent this procedure at a single tertiary care hospital.

\section{INTRODUCTION}

Achalasia cardia $(\overline{A C})$ is a primary motility disorder of esophagus characterized by absence of normal peristalsis and failure of swallow induced relaxation of the lower esophageal sphincter (LES). The underlying mechanism for Achalasia cardia development remains unknown. Current treatment options rely on disruption of the lower esophageal sphincter (LES) to relieve outflow obstruction. To achieve this, over period of time people have tried different modalities of treatment including pharmacological agents, pneumatic balloon dilatation (PBD), open and then laparoscopic Heller's myotomy (LHM). POEM (Per Oral Endoscopic Myotomy) was first described in 2007 and soon emerged as the choice of treatment for primary achalasia cardia (AC). POEM showed excellent short-term efficacy with very good results. But postprocedure GERD has become the point of contention and has not been studied well $(1,2.3)$. In this prospective study we have analyzed outcome of patients undergone POEM for primary Achalasia cardia (AC) at a tertiary care center.

\section{MATERIALS AND METHODS}

In our study we analyzed prospectively collected data of all 50 patients who underwent POEM at our center from October 2017 to March 2020.

Exclusion criteria: - Patients unfit for General anesthesia, large sigmoid esophagus, patients on oral anti coagulation therapy, young age- below 10 years.

Diagnosis was made by gastroduodenoscopy and Highresolution manometry (HRM) in all patients. Eckardt score was used to record symptom severity.

\section{Eckardt Score}

\begin{tabular}{|c|c|c|c|c|}
\hline Score & Dysphagia & $\begin{array}{c}\text { Regurgita } \\
\text { tion }\end{array}$ & $\begin{array}{c}\text { Retro-sternal } \\
\text { pain }\end{array}$ & $\begin{array}{c}\text { Weight } \\
\text { loss in kg }\end{array}$ \\
\hline 0 & None & None & None & None \\
\hline 1 & Occasional & Occasional & Occasional & $<5$ \\
\hline 2 & Daily & Daily & Daily & $5-10$ \\
\hline 3 & Each meal & Each meal & Each meal & $>10$ \\
\hline
\end{tabular}

High Resolution image manometry(HRM)images of achalasia cardia

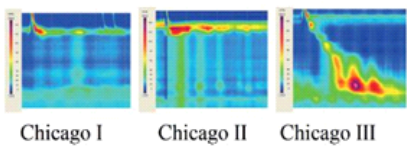

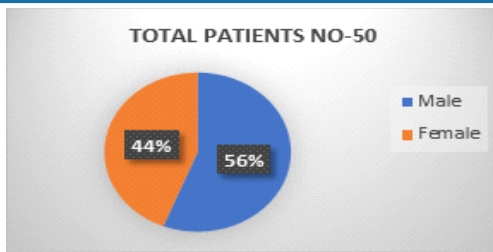

Preoperative Preparation: - Patients were kept on liquid diet one day prior and then nil by mouth 12 hours before the procedure.

All the procedures were done under General anesthesia with Endotracheal intubation with patients in supine position.

Standard high definition Gastroscope (Fujifilm Medical Systems, India) equipped with water jet was used for doing the procedure. A transparent cap from Fujifilms was mounted over the scope for providing better visualization. Intraoperative broad-spectrum antibiotic cover was given to all the patients.

\section{Procedure Steps:}

Stepl: Submucosal injection-dilute methylene blue with normal saline was injected $15 \mathrm{~cm}$ proximal to ' $\mathrm{Z}$ ' line to create sub mucous bleb.

Step2: Mucosal incision- a $1.5 \mathrm{~cm}$ incision was taken over the mucosa using needle knife.

Step3: Submucosal tunnel- the scope was entered into the submucous space and tunnel was extended distally by dissecting submucous fibrous tissue using spray coagulation with a triangular tip (T.T) knife. If any intervening large vessels were encountered, they were coagulated using coagrasper, on soft coagulation mode. Tunnel was extended beyond G-E junction for at least $2 \mathrm{~cm}$, this was confirmed by visualizing characteristic palisade vascular pattern, blanching over gastric mucosa and narrowing at the cardia.

Step4: Myotomy-circular only myotomy was started at least $5 \mathrm{~cm}$ distal to mucosal incision and full thickness myotomy was performed at

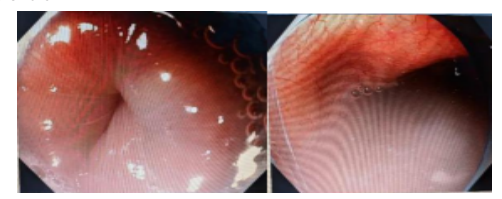


Pre procedure gastroscopy showing cardio spasm with fluid residue in esophagus

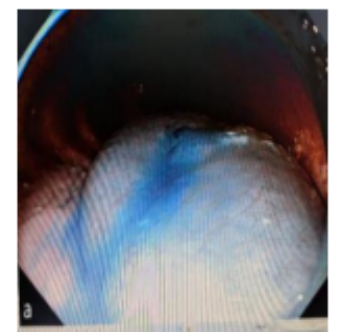

a- Submucous bleb

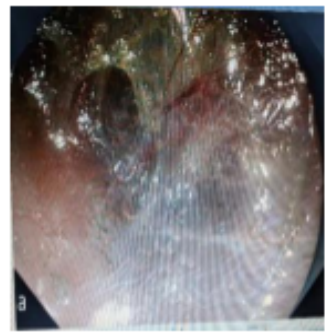

a-Submucous tunneling

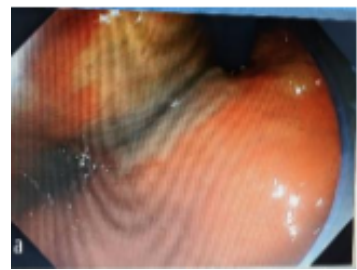

a-Gastric extension

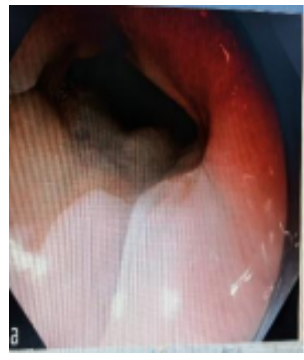

a- loss of spasm,

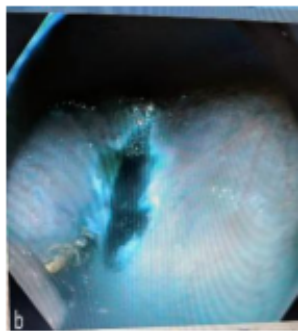

b-Mucosal incision

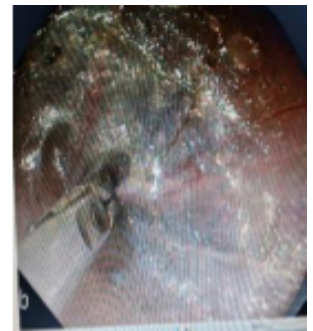

b- coagulation of large vs

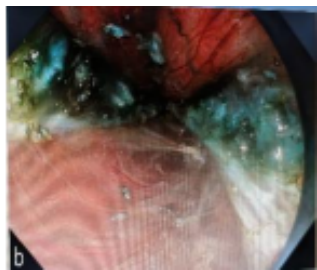

b- Complete Myotomy

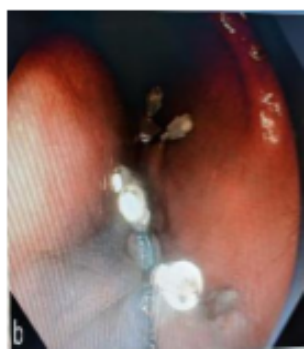

b- Closure of mucosal incision about $3 \mathrm{~cm}$ above the gastro-esophageal (GE) junction and was extended till gastric end of tunnel.

Step5: Closure of mucosal incision - Haemostatis achieved metaculisaly inspecting the tunnel and edges of myotomy. Inadverant mucosal injuries to esophagus and stomach where also looked for. After confirmation these two, mucosal incision was closed by using endoclip (Ez Olympus).

Post-operative management-Patient was kept nil by mouth for 24 hours post procedure.

After 24 hours water soluble radio-opaque dye study was done to rule out any leakage at the mucosal incision.

Oral liquids started on 2 nd postoperative day and the patient was discharged on same day.

All intraoperative results including operative time and complications were recorded.

Follow up:- Patient called for follow up visits on 7th day, 1 month, 3 months and yearly up to 3 years. During follow up visits all patients evaluated.

$7^{\text {th }}$ day :- Only clinical assessment was done

1 month:- Clinical assessment and follow up gastroscopy was done 6 month:- Clinical assessment by Eckardt score and gastroscopy and High resolution myotomy (HRM) were done.

For symptomatic patients 24 hours $\mathrm{PH}$ impedence was done at 6 months interval. DeMeester's score above 14.7 was considered as indicator of GERD.

Adverse events $(A E)-A E$ were defined as those events that required specific intervention or modification of the procedural technique. Both early and late AEs were recorded.

\section{RESULTS}

Total 50 patients underwent POEM in our center. M: F $28: 22$, mean age 43.04 years, (range 22-65 years) Type of AC according to Chicago classification-Type II-47, Type III-3. Prior treatment history was noted in 6 patients PBD-3, LHM- 2 , POEM-1.

Anterior approach was used in majority of patients 47 (94\%) whereas $3(6 \%)$ patients underwent posterior approach. The median operative time of POEM procedure was $83.4 \mathrm{~min}$ (range70mins to 160mins) median length of myotomy was $13 \mathrm{~cm}$ (range 6-2 l cm)

Table 1: Demographics of study patients

\begin{tabular}{|c|c|}
\hline No. of Patients & 50 \\
\hline Mean age, years(range) & $43.04(22-65$ yrs) \\
\hline Male : Female & $28: 22$ \\
\hline Type of AC & 00 \\
\hline Type I & 47 \\
\hline Type II & 03 \\
\hline Type III & \\
\hline Previous history & 00 \\
\hline Botulium injections & 03 \\
\hline Pneumatic balloon dilation (PBD) & 02 \\
\hline LHM & 01 \\
\hline POEM &
\end{tabular}

Technical success rate was $98 \%$ as in one patient procedure could not be completed due to dense submucous fibrosis. There was no significant difference in clinical success rate among subtype II and III upto follow up for 3 years. One patient having failure at one year underwent Re-POEM.

Adverse effects-esophageal mucosal perforation was seen in 2 patients and gastric mucosal perforation in 1 patient which was identified on operation table and closed with endoclips. Insufflation related complication-surgical emphysema was seen in 4 patients which was managed by temporarily stopping procedure for some time. In l patient pneumothorax was developed and managed by inserting ICD tube. Capnoperitonium was seen in 6 patients which was drained using standard Verres needle. One patient developed chest pain after 5 days for which patient was readmitted and medical management was done. There were no major bleeding episodes during or after the procedure. Symptomatic GERD was seen in $10(20 \%)$ patients and erosive esophagitis was seen in $14(28 \%)$ patients. They needed medicines for a short period only. None of these patients needed a long-term medical management and no patient developed any reflux related complications.

\section{DISCUSSION}

Achalasia cardia is progressive irreversible disease of esophageal musculature. It is idiopathic in most cases but can be secondary as seen in after Chagas disease and herpes virus $(4,5)$.

AC has been treated with pharmacological agents like calcium channel blockers and with botulinum toxin but long term success rate has been low with them and there have been few poorly tolerated side effects $(5,6)$ Surgical 
treatment of choice is LHM with partial fundoplication.

For long period of time endoscopic management included only PBD. But response to PBD is less durable than that for LHM and these patients often require re-intervention. (7)

After introduction of POEM by Dr. Inoue in 2008 , a new method in the management of this pathology has opened up. Till date, there have been more than 5000 POEM procedures performed with good results, worldwide. This makes the procedure the most successful version of notes. $(8,9)$

The success of POEM management of Achalasia has been measured primarily by two parameters, pressure of the LES and Eckardts score. (10). A success rate of $93 \%$ with very low incidence of major complication has been observed in most of the series (11). Introduction of High-resolution manometry (HRM) helped us in diagnosing different types of Achalasia. In type III achalasia (Spastic), patients need longer myotomies which is not always possible in LHM. POEM has an advantage in this scenario as we can tailor the length of myotomy as per HRM findings. The clinical success of POEM depends on adequacy of myotomy towards gastric end of the submucosal tunnel. (12), That's why correctly identifying the exact position of GE junction is important. As our experience increased it became easy to identify GE junction, the procedure time also got reduced considerably with that. The effect of prior treatment like PBD or LHM on technical success of POEM appears to be minimal, which is consistent with observations found in previous studies (13 -15) POEM procedure can performed anteriorly or posteriorly and the choice depends on operator's preference. There are no major differences in both technical and clinical success in either of the approaches.

There were no major AEs in our study. Minor bleeding and insufflation related events are part of procedure and are usually inconsequential but for this reason it is important to do the procedure using $\mathrm{CO} 2$ insufflation as air take much longer time to absorb. (16).

GERD is an important long term adverse effect after POEM (17). In our study 10 patients (10/50) $20 \%$ patients had symptomatic GERD and 14 patients (14/50) 28\% patients showed esophageal erosion and all of them were managed by oral medication. None of the patients needed long term medication and no patient has developed any major reflux related complications.

In initial days of procedure, incidence of insufflation related complications was more and operative time was also long but as we got more and more experienced complication rate was reduced and even the procedure time was reduced considerably.

At the end of 3 years follow up patients showing complete absence of symptoms and good weight gain indicate the success of POEM.

\section{CONCLUSION}

POEM is safe effective and durable treatment for Achalasia cardia (AC) with relatively short learning curve. The incidence of GERD doesn't appear to be higher than LHM. Considering the minimal invasive nature and faster recovery of patients, it can be offered as first line of treatment for patient with AC. However long term follow up studies and randomized comparison with established modalities like PBD, LHM will provide conclusive information in that regards.

\section{REFERENCES}

1 Swanstrom LL, Kurian A, Dunst CM et al. Long-term outcomes of an endoscopic myotomy for achalasia: the POEM procedure. Ann Surg 2012;256: $659-667$

2 von Renteln D, Inoue $\mathrm{H}$, Minami $\mathrm{H}$ et al. Peroral endoscopic myotomy for the treatment of achalasia: a prospective single center study. The American journal of gastroenterology 2012;107:411-417
3 Swanstrom L. Poetry is in the air: first multi-institutional results of the peroral endoscopic myotomy procedure for achalasia. Gastroenterology 2013; 145: $272-273$

4- Pandolfino JE, Gawron AJ. Achalasia: a systematic review. JAMA. 2015;313(18):1841-52.doi: 10.1001/jama.2015.2996

5- Vaezi MF, Pandolfino JE, Vela MF. ACG clinical guideline: diagnosis and management of achalasia. Am J Gastroenterol. 2013 Aug; 108(8):1238-49. doi: 10.1038/ajg.2013.196.

6-. Martínek J, Siroký M, Plottová Z, Bures J, Hep A, Spicák J. Treatment of patients with achalasia with botulinum toxin: a multicenter prospective cohort study. Dis Esophagus. 2003;16(3):204-9

7 Yaghoobi M, Mayrand S, Martel M et al. Laparoscopic Heller's myotomy versus pneumatic dilation in the treatment of idiopathic achalasia: a metaanalysis of randomized, controlled trials. GastrointestEndosc 2013; 78: 468 475

8 Inoue H, Minami H, Kobayashi Y, Sato Y, Kaga M, Suzuki M, et al. Peroral endoscopic myotomy(POEM) for esophageal achalasia. Endoscopy. 2010;42(4):265-71.doi: 10.1055/s0029-1244080

9 Mejía R, Donoso A, Manríquez E, Sáez J, Crovari F, Gabrielli M, et al. Miotomíaendoscópicaporvía oral (POEM) para el tratamiento de la acalasia. Experienciaclínicainicial y resultados a cortoplazo. Rev ChilCirugía. 2017;69(5):429-34.doi: 10.1016/j.rchic.2017.03.004

10 Eckardt AJ, Eckardt VF. Treatment and surveillance strategies in achalasia: an update. Nat Rev GastroenterolHepatol. $2011 ; 8(6): 311-9$. doi: 10.1038/nrgastro.2011.68

11 Barbieri LA, Hassan C, Rosati R, Romario UF, Correale L, Repici A. Systematic review and meta-analysis: Efficacy and safety of POEM for achalasia. United European Gastroenterol J. $2015 ; 3(4): 325-34$. doi: European Gastroent
$10.1177 / 2050640615581732$.

12 Teitelbaum EN, Sternbach JM, El Khoury R et al. The effect of incremental distal gastric myotomy lengths on EGJ distensibility during POEM for achalasia. SurglEndosc 2016;30:745-750

13 Sharata A, Kurian AA, Dunst CM et al. Peroral endoscopic myotomy (POEM) is safe and effective in the setting of prior endoscopic intervention. J GastrointestSurg 2013;17:1188-1192

14 Jones EL, Meara MP, Pittman MR et al. Prior treatment does not influence the performance or early outcome of per-oral endoscopic myotomy for achalasia. SurgEndosc 2016;30:1282-1286

15 Fumagalli U, Rosati R, De Pascale S et al. Repeated Surgical or Endoscopic Myotomy for Recurrent Dysphagia in Patients After Previous Myotomy for Achalasia.J GastrointestSurg 2016;20:494-499

16 Binmoeller KF, Bhat YM. Underwater peroral endoscopic myotomy. GastrointestEndosc 2016;83:454

17 Nabi Zaheeretal.Per-oral endoscopic myotomy... Endoscopy International Open 2017;05:E331-E339 